\title{
INVITED COMMENT: Is Bedtime the best time of the day?
}

\author{
BO CARLBERG
}

Department of Public Health and Clinical Medicine, Umeå University, Umeå, Sweden

\section{MATTIAS BRUNSTRÖM}

Department of Public Health and Clinical Medicine, Umeå University, Umeå, Sweden

\section{DOI: $10.30824 / 2003-9$}

In October 2019, European Heart Journal published the Hygia Chronotherapy Trial online before print ${ }^{[1]}$. The results have been widely discussed among researchers, on internet forums, in lay press, and among patients. Here, we argue why the findings should be interpreted with caution, and future studies awaited before changing clinical practice.

The Hygia Chronotherapy Trial, including 19084 participants with high blood pressure, compared intake of all antihypertensive drugs in the morning with intake of at least one drug at bedtime. All participants underwent 48-hour ambulatory blood pressure monitoring at baseline and repeatedly during the study. The median follow-up time was 6.3 years.

At the end of the study, the morning group were treated with on average 1.80 antihypertensive drugs whereas the bedtime group were treated with 1.71 drugs $(p<0001)$. The mean blood pressures at the end of the study were:

\begin{tabular}{l|l|l} 
& Morning group & Bedtime group \\
\hline Office Blood & $143.2 / 82.4$ & $140.0 / 81.4$ \\
Pressure & $\mathrm{mm} \mathrm{Hg}$ & $\mathrm{mm} \mathrm{Hg}$ \\
\hline Daytime ABPM & $129.5 / 76.7$ & $129.2 / 76.3$ \\
& $\mathrm{~mm} \mathrm{Hg}$ & $\mathrm{mm} \mathrm{Hg}$ \\
\hline Nighttime ABPM & $118.0 / 66.1$ & $114.7 / 64.5$ \\
& $\mathrm{~mm} \mathrm{Hg}$ & $\mathrm{mm} \mathrm{Hg}$
\end{tabular}

Taking at least one antihypertensive drug at bedtime was associated with a very pronounced decrease of cardiovascular morbidity and mortality. Also, the effect on total mortality was extraordinary. Below are some selected individual outcomes:
Selected oucome events

\begin{tabular}{l|l}
\hline $\begin{array}{l}\text { All-Cause Mortality } \\
\text { (Adjusted Hazard } \\
\text { Ratio, 95\% Cl) }\end{array}$ & $0.55(0.48-0.63)$ \\
\hline $\begin{array}{l}\text { Cardiovascular mortality } \\
\text { (Adjusted Hazard } \\
\text { Ratio, 95\% Cl) }\end{array}$ & $0.44(0.34-0.56)$ \\
\hline $\begin{array}{l}\text { Ischemic Stroke } \\
\text { (Adjusted Hazard } \\
\text { Ratio, 95\% Cl) }\end{array}$ & $0.54(0.42-0.69)$ \\
\hline $\begin{array}{l}\text { Hemorrhagic Stroke } \\
\text { (Adjusted Hazard } \\
\text { Ratio, 95\% Cl) }\end{array}$ & $0.39(0.23-0.65)$ \\
\hline $\begin{array}{l}\text { Myocardial infarction } \\
\text { (Adjusted Hazard } \\
\text { Ratio, 95\% Cl) }\end{array}$ & $0.66(0.52-0.84)$ \\
\hline $\begin{array}{l}\text { Heart Failure (Adjusted } \\
\text { Hazard Ratio, 95\% } \\
\text { Cl) }\end{array}$ & $0.58(0.49-0.70)$ \\
\hline $\begin{array}{l}\text { Angina Pectoris } \\
\text { (Adjusted Hazard } \\
\text { Ratio, 95\% Cl) }\end{array}$ & $0.65(0.51-0.83)$ \\
\hline
\end{tabular}

Selected composite outcome events

\begin{tabular}{l|l}
\hline $\begin{array}{l}\text { Total events (Adjusted } \\
\text { Hazard Ratio, 95\% Cl): }\end{array}$ & $0.58(0.54-0.62)$ \\
\hline $\begin{array}{l}\text { CVD-outcome events* } \\
\text { (Adjusted Hazard } \\
\text { Ratio, 95\% Cl): }\end{array}$ & $0.55(0.50-0.61)$ \\
\hline $\begin{array}{l}\text { Stroke (Adjusted Hazard } \\
\text { Ratio, 95\% Cl): }\end{array}$ & $0.51(0.41-0.63)$ \\
\hline $\begin{array}{l}\text { Coronary events (Adjusted } \\
\text { Hazard Ratio, 95\% Cl): }\end{array}$ & $0.56(0.49-0.64)$ \\
\hline
\end{tabular}

*CVD Outcome (CV Mortality, Myocardial infarction, Coronary revascularization, heart failure and stroke)

If the results are valid, they imply that there could be very important pathophysiological mechanism in 
hypertension treatment that has been less known until now. This may be true, but several important questions need to be answered before such conclusions can be drawn.

It is difficult to assess the methods and results presented in the article, mainly because it is not reported transparently according to common standards (CONSORT) ${ }^{[2]}$. Therefore, some questions are still unanswered.

\section{Is this a randomized controlled trial?}

Most people read the paper as if it was a randomized controlled trial, but the word "randomization" appear only once, in the context of the PROBE abbreviation. Instead, words like "assigned" and "allocated" are used throughout the text; in the abstract, the study is defined as a "multicenter, controlled, prospective endpoint trial". Whether randomization was adequately performed is not clear in the methods paper. Here, the randomization procedure is described as if there are several short-term trials testing different agents separately. A random code has been generated at the coordinating center, but it is not clear if allocation was concealed to physicians at participating centers.

\section{How were losses to follow up handled?}

There are no data presenting the number of participants lost to follow-up. In the flow diagram, 84 out of 19168 participants were excluded as they had less than 1 year follow-up duration. Does this mean no one were lost with more than 1 year follow-up? It is not obvious why the 84 participants with less than 1 year follow-up were excluded; the conventional approach would be to include them and censor at last follow-up.

\section{Were there non-protocol differences between treatment groups?}

There is no obvious difference in non-study treatments between the two groups as far as reported, with one exception. Participants in the morning group were given more ACE-inhibitors, betablockers and diuretics and the bedtime group received more calcium antagonists compared with the other group. If this has any impact on the outcome is unknown, but it is not reasonable that this minor difference could account for such huge difference in cardiovascular outcomes between the groups.

\section{Statistical issues}

The results are presented as hazard ratios derived through a Cox-model adjusted for nine different covariates, including asleep SBP and sleep-time SBP decrease. Firstly, presenting adjusted hazard ratios, without crude numbers and unadjusted estimates, is not transparent and therefore difficult to appraise. Some of these data have been added in a letter published online, but mortality data are still lacking. Secondly the number of participants with composite outcomes are the same as the sum of the individual outcomes included in each composite outcome analysis. This could not be the case in time-to-first event analyses, because one participant can only contribute with one event. If the number of events for individual outcomes equate the number in the composite outcome, it implicitly means that no one died after a cardiovascular event. Thirdly, by hand counting, it looks like the risk for non-cardiovascular deaths would be approximately $40 \%$ lower in the evening group. What other deadly outcomes did the intervention have impact on?

\section{Ethical issues}

Why was the study expanded? In randomized controlled trials with important patient-related outcomes, like cardiovascular disease and mortality, an Independent Data and Safety monitoring Board (DSMB) should monitor the outcomes at regular intervals. A DSMB assures that unnecessary harm is not caused by the intervention, or from not receiving the intervention, by stopping the trial once differences between groups are established. Different studies have different rules for early termination. The most conservative outcome used in cardiovascular outcome trials is all-cause mortality. As the effect on all-cause mortality in the Hygia Chronotherapy trial was very large, with a narrow confidence interval (see above), the study should have been stopped years before it actually was stopped. Instead, comparing the number of participants reported in the article with the number of participants in the methods paper and previous records on clinicaltrials.gov, it seems as if the study 
was expanded almost four-fold from an original estimated 5000 participants.

To conclude, it is difficult to draw conclusions from this very interesting study as it is not transparently reported. With many unanswered questions, it is too early to change clinical practice. There are two ongoing studies testing similar hypotheses, the BedMed and TIME study. It will be very important to follow the outcome of these trials.

Bo Carlberg - bo.carlberg@umu.se

\section{References}

1. Hermida RC, Crespo JJ, Domínguez-Sardina $M$ et al. Bedtime hypertension treatment improves cardiovascular risk reduction: the Hygia Chronotherapy Trial. Eur Heart J 2019; doi: 10.1093/eurheartj/ehz754
2. Schulz KF, Altman DG, Moher D et al. CONSORT 2010 Statement: Updated Guidelines for Reporting Parallel Group Randomized Trials. Ann Intern Med 2010;152:726-32. doi: 10.1097/AOG.0b013e3181d9d421

\title{
INVITED COMMENT: \\ New NICE Guideline opts for stability
}

\author{
JOHN CHALMERS \\ The George Institute for Global Health \\ The University of NSW, Sydney \\ Australia
}

Following the publication of the SPRINT study in the New Engl J Med in 2015', a number of the major international guidelines have gradually been revised, beginning with those of the American College of Cardiology and American Heart Association (AHA) in $2017^{2}$. These were followed by the guidelines of the European Societies of Cardiology and of Hypertension (ESC/ESH) in $2018^{3}$ and then by the British guidelines for "Hypertension in Adults: diagnosis and management" from the National Institute for Health and Care Excellence ('NICE')'.

One of the attractive features of NICE is that these guidelines are written in plain and simple English and are aimed as much at patients and their families and carers, as they are at hypertension specialists, general practitioners or other health care professionals ${ }^{4}$. Another attractive feature is their relative brevity and simplicity, though that is achieved in part by referring the reader to a variety of separate NICE guidelines such as those on "chronic kidney disease in adults", or "cardiovascular disease" or "alcoholuse disorders" or on "stop smoking interventions and services". On the other hand, these new NICE guidelines do apply to people with type 2 diabetes ${ }^{4}$.

\section{Opportunities for change that were resisted}

These are no major dramatic changes in the updated NICE guidelines though they do refer to the relevant literature, albeit with a conservative bent. The major areas where possible change has been resisted include the following:

\section{Measurement of Blood Pressure}

The 2019 NICE guideline does not consider the possible use of "Unattended Automated Office Blood Pressure Measurement", (AOBPM) the method used in SPRINT \& recommended in the ACC/AHA 2017 guidelines as well as in the 2016 Canadian Guidelines 5 , on the grounds that this method of measuring BP would be difficult to translate into UK clinical practice. They prefer the more traditional use of automated devices or of manual measurement using direct auscultation over the brachial artery ${ }^{4}$. That may well be true but a recommendation from NICE in 2019 encouraging the use of AOBPM might have provided valuable leadership. It is interesting to note that in a recent survey of patients with 